\title{
Актуальная стратегия эрадикации сформированных биопленок при использовании магнитных наноструктур
}

\author{
() В. И. Румянцева, Е. И. Кошель
}

Национальный исследовательский университет ИТМО

Россия, 197101 г. Санкт-Петербург, проспект Кронверкский, 49.

\section{Email:viktoriya_rumyantceva@scamt-itmo.ru}

В качестве наиболее эффективной стратегии борьбы с биопленками предложен магнитоуправляемый керамический нанокомпозит с контролируемыми параметрами релиза активного компонента под воздействием высокочастотного магнитного поля.

Ключевые слова: биопленки, наноструктурные композиты, антибактериальные свойства, контролируемые параметры, биоциды.

Образование биопленок на биотических и абиотических поверхностях является критической проблемой в самых разных областях, от сельского хозяйства и промышленности до медицины. Поскольку биопленки оптимизируют выживание большинства микроорганизмов, колонизации могут подвергаться любые поверхности, включая человеческое тело и медицинские устройства. Инфекция имплантатов абиотических устройств, находящихся в прямом контакте с пациентом, является одним из серьезных и частых медицинских осложнений [1-3]. Ткани и органы человека также подвержены колонизации микроорганизмами, что провоцирует воспаление при таких заболеваниях, как муковисцидоз, отит и перикардит [4].

Терапия воспаления, связанного с биопленкой, представляет собой серьезную проблему, поскольку бактерии внутри биопленки в 100-1000 раз более устойчивы к обычным антибактериальным агентам, эффрективным против свободно плавающих (планктонных) бактериальных клеток. Низкая эфрфективность биоцидов против биопленок определяется их механическими и химическими свойствами, что препятствует глубокому проникновению антибиотика. Еще одна важная проблема - клетки с пониженным метаболизмом, известные как «персистеры» [5]. Следовательно, для эфрфективной антибактериальной терапии биопленки следует предварительно дезинтегрировать. Однако агрессивные антибактериальные составы и грубое механическое действие недопустимы для использования внутри организма [6-8]. Практического и нетравматичного подхода к решению этой проблемы пока нет. Наиболее эфрфективные стратегии борьбы с биопленками по-прежнему основаны на травматичных и дорогостоящих процедурах удаления биопленок или замены пораженных поверхностей $[4,8-11]$. С увеличением числа имплант-зависимых операций и осложнений, вызванных образованием и развитием биопленки, необходимость в разработке эффективной терапии постоянно возрастает. Описанные выше проблемы можно решить с помощью механического разрушения биопленки с последующим интенсивным высвобождением биоцидных компонентов.

Биоцид-конъюгированные наночастицы и наноструктурные композиты, энтрапированные активными веществами являются отличной возможностью для неинвазивной терапии, поскольку благодаря небольшому размеру и уникальным фризико-химическим 
свойствам такие системы могут проявлять ценные свойства в биомедицинской практике [12-15].

В настоящей работе рассмотрены механизмы влияния нанокомпозитов на основе наночастиц магнетита на бактериальные клетки и их консорциумы: механическая дезинтеграция, синергетическое антибактериальное воздействие компонентов композита и др., а также разница во влиянии на биопленку составляющих потенциального композита в отдельности (рис. 1).

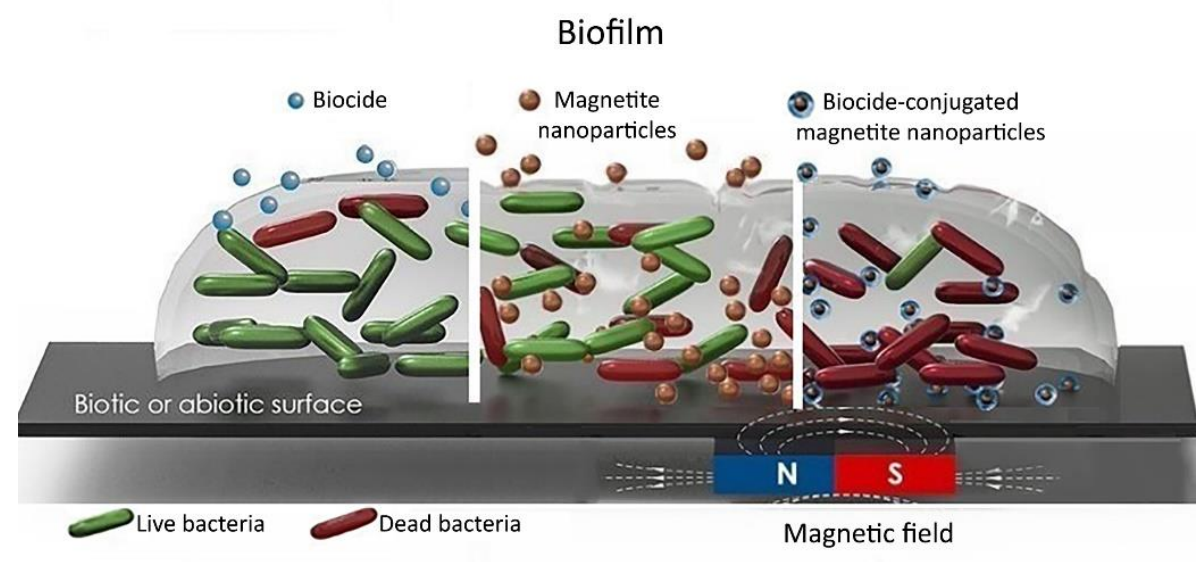

Рис. 1. Разница во влиянии антибиотика, магнитных наночастиц и композита на деградацию биопленки.

В результате проведенного сравнительного анализа подобраны материалы для разработки новых высокоэффективных композитов. Среди них наиболее перспективными выделены магнитные биосовместимые наночастицы для придания композиту уникальных свойств, карбонат кальция и его производные в виде керамического каркаса. Оптимальный протокол получения нанокомпозита состоит из синтеза наночастиц магнетита методом соосаждения с помощью ультразвука [16] и синтеза микрочастиц на их основе методом соконденсации при добавлении насыщенных растворов хлорида кальция, карбоната натрия и биоактивного соединения [17].

В ходе изучения свойств полученного наноструктурированного композита отмечены механизмы медленного, самопроизвольного, и быстрого, инициируемого, релиза активного компонента через матричный каркас (рис. 2). Отмечены преимущества работы магнитной системы, позволяющей производить локализацию биоцидных компонентов в очаге инфицирования. 

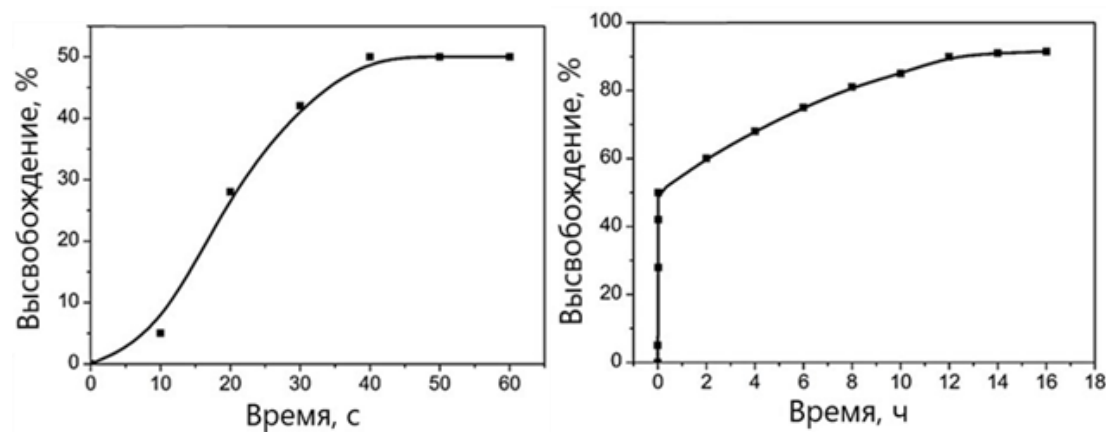

Рис. 2. Кривые высвобождения биоцидного компонента магнитного керамического композита: 1 - пассивный релиз; 2 - инициируемое высвобождение.

Эфффективность антибактериального действия разработанного нанокомпозита против сформированных биопленок определялась на модельных штаммах микроорганизмов: грамположительных S. aureus и грамотрицательных E. coli. В качестве биоцида был использован антибиотик ципрофлоксацин (ЦФ), обладающий широким спектром действия против различных видов бактерий. Биомассу биопленки и количество живых клеток в ней исследовали через 24 ч инкубации с исследуемыми образцами (табл. 1). Количество биомассы анализировали по количеству связывающего красителя, кристаллического фииолетового, оставшегося после промывки биопленок. Чем выше эффрективность композита или антибиотика, тем меньшее количество красителя связывается с биопленкой, что определяет количественную характеристику последней.

Таблица 1. Эфрфективность нанокомпозита против образованных биопленок E. coli и S. aureus

\begin{tabular}{|c|c|c|c|}
\hline \multirow{2}{*}{ Состав образца } & \multicolumn{2}{|c|}{$\begin{array}{c}\text { Масса биопленки после обработки } \\
\qquad(\mathrm{M} \pm \mathrm{SD})\end{array}$} & \multirow{2}{*}{$\begin{array}{l}\text { Эффрективность ЦФ в составе } \\
\text { нанокомпозита по сравнению } \\
\text { со свободной фрормой ЦФ, \% }\end{array}$} \\
\hline & $\begin{array}{c}\text { ЦФ в с свободной } \\
\text { форме }\end{array}$ & $\begin{array}{l}\text { ЦФ в составе } \\
\text { нанокомпозита }\end{array}$ & \\
\hline \multicolumn{4}{|c|}{ E. coli } \\
\hline- & \multicolumn{2}{|c|}{$0,951 \pm 0,07$} & - \\
\hline нанокомпозит & \multicolumn{2}{|c|}{$0,516 \pm 0,05$} & - \\
\hline $\begin{array}{l}\text { нанокомпозит с } \\
0,15 \text { мкг/мл ЦФ }\end{array}$ & $0,443 \pm 0,02$ & $0,275 \pm 0,02$ & 38 \\
\hline \multicolumn{4}{|c|}{ S. aureus } \\
\hline- & \multicolumn{2}{|c|}{$1,575 \pm 0,08$} & - \\
\hline нанокомпозит & \multicolumn{2}{|c|}{$0,370 \pm 0,02$} & - \\
\hline $\begin{array}{c}\text { нанокомпозит с } \\
\text { 2,5 мкг/мл ЦФ }\end{array}$ & $0,853 \pm 0,06$ & $0,239 \pm 0,01$ & 72 \\
\hline
\end{tabular}

Как и ожидалось, антибиотик, иммобилизованный в нанокомпозите, показал более высокую эффективность против образовавшихся биопленок, чем антибиотик в его исходной фрорме. На основании полученных данных можно судить о синергетическом дей- 
ствии нанокомпозита и ципрофлоксацина, в первую очередь, для грамположительных видов бактерий - эфрфективность по отношению к $S$. aureus составила $72 \%$.

Таким образом, были доказаны преимущества применения нанокомпозитных материалов для комплексной борьбы с биопленочными образованиями, в частности на абиотических поверхностях, что является перспективным заделом для дальнейших исследований в данной области, в том числе проводимых на антибиотикорезистентных штаммах микроорганизмов и с применением других биоцидных компонентов, а также проводимых in vivo для всесторонней оценки возможности применения разработанного комплекса в фрармакологической и медицинской практике.

Работа выполнена при фринансовой поддержке Российского научного фоонда, грант № 19-74-00125.

\section{Литература}

1. Arciola C. R., Campoccia D., Ehrlich G. D. Biofilm-based implant infections in orthopaedics // Biofilm-based healthcare-associated infections. 2015. Pp. 29-46.

2. Arciola C. R., Campoccia D., Montanaro L. Implant infections: adhesion, biofilm formation and immune evasion // Nature Reviews Microbiology. 2018. Vol. 16. Pp. 397-409.

3. Montanaro L., Speziale P., Campoccia D. Scenery of Staphylococcus implant infections in orthopedics // Future Microbiology. 2011. Vol. 6. Pp. 1329-1349.

4. Bouza E., Garcia-Garrote F., Cercenado E. Pseudomonas aeruginosa: a survey of resistance in 136 hospitals in Spain // Antimicrobial Agents and chemotherapy. 1999. Vol. 43. Pp. 981.

5. Prax M., Bertram R. Metabolic aspects of bacterial persisters // Frontiers in cellular and infection microbiology. 2014. Vol. 4. Pp. 148.

6. Römling U., Kjelleberg S., Normark S. Microbial biofilm formation: a need to act // Journal of internal medicine. 2014. Vol. 276. Pp. 98-110.

7. Ribet D., Cossart P. How bacterial pathogens colonize their hosts and invade deeper tis-sues // Microbes and infection. 2015. Vol. 17. Pp. 173-183.

8. Percival S. L., Suleman L., Vuotto C. Healthcare-associated infections, medical devices and biofilms: risk, tolerance and control // Journal of medical microbiology. 2015. Vol. 64. Pp. 323-334.

9. Høiby N., Bjarnsholt T., Moser C. ESCMID guideline for the diagnosis and treatment of biofilm infections 2014 // Clinical microbiology and infection. 2015. Vol. 21. Pp. S1-S25.

10. Mermel L. A., Allon M., Bouza E. Clinical practice guidelines for the diagnosis and management of intravascular catheter-related in-fection: 2009 update by the Infectious Diseases Society of America // Clin Infect Dis. 2009. Vol. 49. Pp. 1-45.

11. Lebeaux D., Ghigo J. M., Beloin C. Biofilm-related infections: bridging the gap between clinical management and fundamental aspects of recalcitrance toward antibiotics // Microbiology and molecular biology reviews: MMBR. 2014. Vol. 78. Pp. 510. 
12. Chifiriuc M. C., Grumezescu A. M., Andronescu E. Water dispersible magnetite nanoparticles influence the efficacy of antibiotics against planktonic and biofilm embedded Enterococcus faecalis cells // Anaerobe. 2013. Vol. 22. Pp. 14-19.

13. Niemirowicz K., Durnas B., Tokajuk G. Magnetic nanoparticles as a drug delivery system that enhance fungicidal activity of polyene antibiotics // Nanomedicine: Nanotechnology, Biology and Medicine. 2016. Vol. 12. Pp. 2395-2404.

14. Cotar A. I., Grumezescu A. M., Andronescu E. Nanotechnological solution for improving the antibiotic efficiency against biofilms developed by gram-negative bacterial strains // Lett. Appl. NanoBioSci. 2013. Vol. 2. Pp. 97-104.

15. Rumyantceva V. I., Rumyantceva V. I., Koshel E. I. Biocide-conjugated magnetite nanoparticles as an advanced platform for biofilm treatment // Therapeutic delivery. 2019. Vol. 10. Pp. $241-250$.

16. Shapovalova O. E., Drozdov A. S., Brushkova E. A. Room-temperature fabrication of magnetite-boehmite sol-gel composites for heavy metal ions removal // Arab. J. Chem. 2020. Vol. 13. Pp. 1933-1944.

17. Rumyantceva V. I., Rumyantceva V. I., Andreeva Y. I. Magnetically Controlled Carbonate Nanocomposite with Ciprofloxacin for Biofilm Eradication // International Journal of Molecular Sciences. 2021. Vol. 22. Pp. 6187.

\title{
Actual strategy for formed biofilms eradication using magnetic nanostructures
}

\author{
V. I. Rumyantceva, E. I. Koshel
}

ITMO University

49-A Kronverkskiy prospekt, 197101 St. Petersburg, Russia.

Email:viktoriya_rumyantceva@scamt-itmo.ru

A magnetically controlled ceramic nanocomposite with controlled release parameters of the active component under the influence of a high-frequency magnetic field has been proposed as the most effective strategy for combating biofilms.

Keywords: biofilms, nanostructured composites, antibacterial properties, controlled parameters, biocides. 